\title{
Spatial Variability of Soil Physical Properties Based on GIS and Geo-Statistical Methods in the Red Beds of the Nanxiong Basin, China
}

\author{
Ping Yan ${ }^{1}$, Hua Peng ${ }^{1}$, Luobin Yan ${ }^{2 *}$, Kairong Lin ${ }^{3}$ \\ ${ }^{1}$ School of Geography and Planning, Sun Yat-sen University, Guangzhou, China \\ ${ }^{2}$ School of Geographical Sciences, Southwest University, Chongqing, China \\ ${ }^{3}$ School of Civil Engineering, Sun Yat-sen University, Guangzhou, China,
}

Received: 16 March 2018

Accepted: 13 June 2018

\begin{abstract}
Spatial variability of soil has an important influence on the structure and function of soil. The spatial distribution of soil physical properties provides basic and useful information relevant to soil management and ecological protection. A typical red beds basin was selected for this study, soil samples at $0-20 \mathrm{~cm}$ were taken from 150 locations in the northeast part of Nanxiong Basin, in which GIS and geostatistics were used to analyze the spatial variability of the soil physical properties. The results show that the coefficients of variation of soil bulk density, total porosity and capillary porosity are $9.82 \%, 4.47 \%$, and $3.72 \%$, respectively, which indicate weak variation. Pearson correlation indicated that soil bulk density was significantly positively correlated with soil moisture and capillary water capacity $(\mathrm{p}<0.01)$, with correlation coefficients of 0.85 and 0.91 , respectively, but was significantly negatively correlated with total porosity, capillary porosity and non-capillary porosity, with correlation coefficients of 0.82 , 0.71 and 0.94 , respectively $(\mathrm{p}<0.01)$. The spatial distributions of soil physical properties using ordinary kriging $(\mathrm{OK})$ and empirical bayesian kriging $(\mathrm{EBK})$ methods were subjected to comparative analysis. In addition, different cross-validation indicators were applied to assess the performance of different interpolation methods. Cross-validation demonstrated that EBK performed better than OK. And EBK produced smaller regions of predicted soil physical properties than $\mathrm{OK}$, highlighting the necessity of choosing the appropriate methods in studying the spatial distribution of soil properties.
\end{abstract}

Keywords: soil physical properties, purple soil, kriging interpolation, empirical bayesian kriging, Nanxiong Basin

*e-mail: yanluobin@swu.edu.cn 


\section{Introduction}

Soil physical properties are an important set of soil properties that affect many physical, chemical and biological processes in soils $[1,2]$. One specific property of soil is known as the spatial variability of soil properties, which is caused by the complex formation process of soils [3]. Although the parent material and climate determine the spatial heterogeneity of soil properties on a large scale, in a specific ecological system soil spatial heterogeneity is affected by topography and biotic factors, especially at the finer scale. The spatial heterogeneity of soil at different scales has an important influence not only on the structure and functions of soil, but also spatial patterns of vegetation [6, 7]. Knowledge of soil variability is necessary for practical applications as well as for model development [8]. Therefore, understanding and utilizing the spatial variability of soil properties may help to improve land use efficiency, increase soil quality and benefit ecological environment protection [9, $10]$.

Geostatistics is a mathematical method based on the theory of regionalized variables and semi-variance functions [11]. It provides the basis for the interpolation and interpretation of the spatial variability of soil properties [12]. This method can be used to study the data of both randomness and structure, which makes up for the defects of classical statistical spatial orientation analysis. In addition, geostatistics is an effective tool to study the spatial variability of soil properties, as this characteristic can be considered via the spatial auto-correlation among the variables [13]. The study of spatial variability of soil properties using geostatistics and GIS technology has become one of the hot topics in the fields of soil science and agricultural ecology.

In the 1970s the theory of geostatistics was initially applied to soil science, and used to study the spatial variability of soil properties [14-16]. Based on that research, many geostatistical techniques have been developed to predict the spatial variability of soil properties, such as ordinary kriging (OK) [6, 17], cokriging [18, 19], area-to-point kriging [20], inverse distance weighting (IDW) [21], artificial neural network method [22] and pedo-transfer functions [23]. Among them, OK has been most widely used [24, 25]. Meanwhile, empirical bayesian kriging (EBK) as a method of geostatistical interpolation automates the most difficult aspects of composing an adequate kriging model. Due to the interpolation of available observations, this makes the method independent of trends and offers hope for a significant expansion of the application areas [26]. Although EBK was successfully used for analysis of humus distribution [26] and in benthos mapping [27], few scholars have used this method to study the spatial variability of soil. Thus, this study attempts to apply the OK and EBK methods in a comparative study of soil physical properties in order to explore the best research methods to study the spatial variation of soil properties at a fine scale.

Since the 1980s, some scholars in China have adopted the theory and technical system of soil spatial variability, and have done a lot of meaningful research on the spatial variability of soil properties in China, such as black soil in northeastern China [28], northwestern desert soil [29], hilly red soil [30], karst mountainous soil [31], loess plateau soil [32-34], croplands of the black soil [34], plain soil [35-37] and alpine steppe soil [38]. Although previous studies have looked at spatial variations of soil nutrient distribution [39] and soil organic carbon[40], few studies have been done on the spatial variability of soil physical properties in the red beds region. The exposure of red beds covers $9.16 \times 10^{5} \mathrm{~km}^{2}$, which accounts for $9.5 \%$ of the total land area of China. Among them, under the influence of temperature difference and moisture, the redbed softrock disintegrates easily [2], which causes the high erosion rates of purple soil [3]. The typical purple soil developed on red beds is particularly prone to erosion due to intensive cultivation and the wet climate of the area [41], and previous research has proven the relationship between soil physical properties and erodibility $[42,43]$. Thus, more studies are needed of the spatial variations of soil physical properties and choosing the appropriate methods for interpolation in purple soil areas.

Considering the importance of obtaining soil physical properties in the red beds region, this study was undertaken to compare the performance of two interpolation methods, including ordinary kriging (OK) and empirical Bayesian kriging (EBK), in producing an accurate distribution map of soil physical properties in the red beds region. In addition, the spatial distribution of soil physical properties was generalized and the impact of human disturbance was discussed. The results can then provide useful information valuable for improving land management practices.

\section{Materials and Methods}

\section{Experimental Site}

The experimental site is located in Nanxiong Basin, which is a typical red-bed basin with a severe soil erosion problem due to its dominant purple soil texture (Calcaric Regosols in FAO taxonomy), fragile ecological environment, severe soil erosion, and the fact that red clay-rich sediments of the parent rock are mainly distributed in the central part of the basin. It has an elevation of 48-1421 $\mathrm{m}$ above sea level [44] with a moist, subtropical monsoon climate, and four distinct seasons, including a long summer and short winter, and a fast autumn transition. Average temperature is $19.6^{\circ} \mathrm{C}$, maximum temperature is $39.6^{\circ} \mathrm{C}$, and the extreme minimum temperature is $-6.2^{\circ} \mathrm{C}$. 


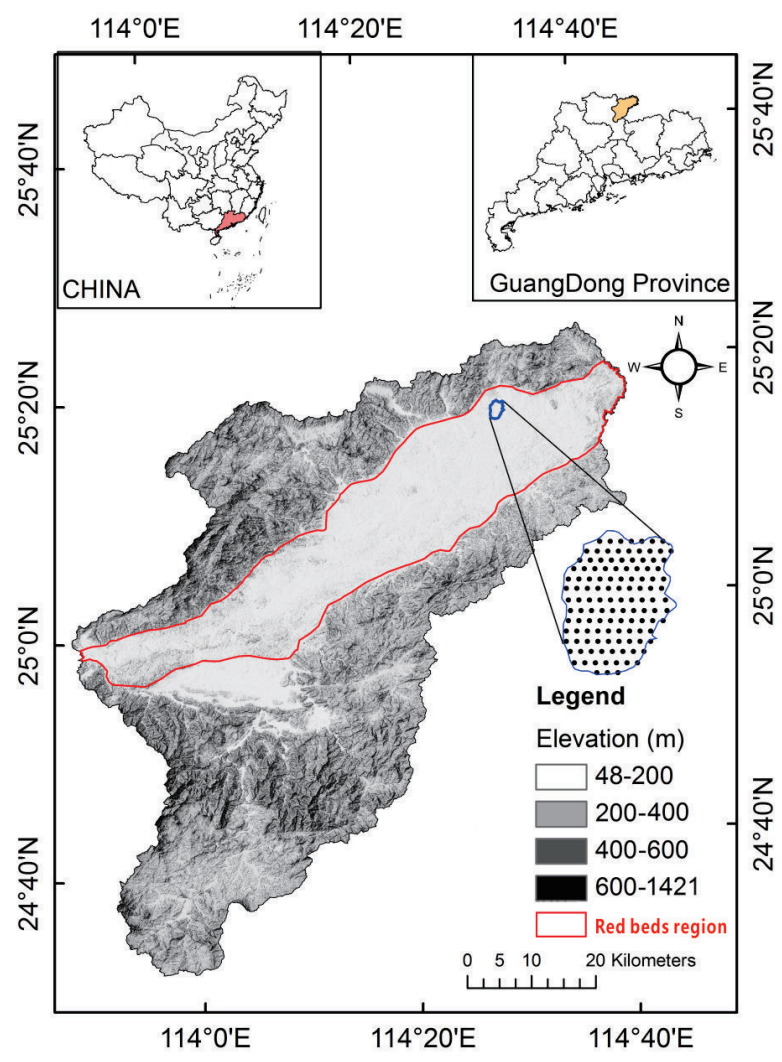

Fig. 1. Location of the study area.

The average annual evaporation is $1678.7 \mathrm{~mm}$, while the average annual rainfall is $1555.1 \mathrm{~mm}$.

\section{Sample Collection}

The sampling distance was set at $30 \mathrm{~m}$, and a total of 150 samples was collected by taking the field size and sampling uniformity into consideration. Sampling depth ranged from $0 \mathrm{~cm}$ to $20 \mathrm{~cm}$. The sampling method corresponded to the traditional mixed sampling method, whereby a total of 5 sub-samples are mixed to form a sample for each sampling point [45]. The distribution map of the sampling points was made in the ArcGIS 10.1 platform.

\section{Determination Methods}

\section{Ring Knife Method}

Soil bulk density, soil moisture capillary porosity and capillary water capacity were mainly determined using the methods of ring knife and oven-drying [46].

\section{Semi-Variogram}

As the theoretical basis of geostatistics, semivariogram is often used to represent the spatial variability and correlation of regionalized variables on a certain scale. Also, it can determine the spatial structure of soil physical properties. Well-known theoretical models such as spherical, exponential and Gaussian are commonly used to calculate experimental semi-variograms using the observed data [11]. The variation function $\gamma(\mathrm{h})$ can be defined as $1 / 2$ of random function $\mathrm{Z}(\mathrm{xi})$. The formula is as follows:

$$
\gamma(h)=\frac{1}{2 \mathrm{~N}(h)} \sum_{\mathrm{i}=1}^{\mathrm{N}(h)}\left[\mathrm{Z}\left(\mathrm{x}_{\mathrm{i}}\right)-\mathrm{Z}\left(\mathrm{x}_{\mathrm{i}}+h\right)\right]^{2}
$$

In the formula, $h$ is the lag and $N(h)$ is the number of pairs of sample points separated by $\mathrm{h}$ [6]. Z (xi) is the value of position $x i$ and $Z(x i+h)$ is the value of the distance $\mathrm{xi}+\mathrm{h}$.

\section{Ordinary Kriging}

As the most widely used kriging method, based on the weighted average of adjacent observed points within a given area [47], OK can provide an estimation at an unobserved location of variable z. Kriging interpolation is given a random process under the conditions of the measured value, and obtains the unbiased optimal estimation by using known sample point $Z$ (xi) data to estimate the sample $\mathrm{Z}(\mathrm{xi}+\mathrm{h})$ value, according to the following formula:

$$
Z\left(x_{i}+h\right)=\sum_{i=1}^{\mathrm{N}} \lambda_{i} Z\left(x_{i}\right)
$$

Among them, $\lambda \mathrm{i}$ is the weight of the measured sample points, which is determined by the analysis of variance function. The OK interpolation is a local linear optimal unbiased estimation method for a single variable. A detailed theoretical description of the kriging algorithms was provided by Webster and Oliver (2001) [48].

\section{Empirical Bayesian Kriging}

The EBK method differs from classical kriging methods by accounting for the error introduced by estimating the semi-variogram model. It is an interpolation method that accounts for the error in estimating the underlying semi-variogram through repeated simulations. This method is implemented as a module in the geostatistical analyst toobox of ArcGIS10.1 (ESRI) platform. This process entails the following steps:

(1) A semi-variogram model is estimated from the data.

(2) Using this semi-variogram, a new value is simulated at each of the input data locations.

(3) A new semi-variogram model is estimated from the simulated data. A weight for this semi-variogram is then calculated using Bayes' rule, which shows how likely the observed data can be generated from the semi-variogram [49]. 


\section{Data Analysis}

The datasets were analyzed to determine the descriptive univariate statistical parameters, i.e., maximum, minimum, mean, median, standard deviation (S.D.) and coefficient of variation (C.V.). The Kolmogorov-Smirnov (K-S) method, together with skewness and kurtosis values, were used to evaluate the normality of the datasets [50].

The relationships among soil physical parameters were examined using Pearson's correlation analysis. All statistical analyses were performed using the software SPSS Statistics Client 19.0 (SPSS, Inc., Chicago, USA). The semi-variance function and the optimal run variance model were analyzed using ArcGIS 10.1, while the OK and EBK interpolations were performed using ArcGIS 10.1 geostatistical and spatial analyst tools.

\section{Results and Analysis}

\section{Classical Statistical Analysis of Soil Physical Properties}

As shown in Table 1, the maximum value of bulk density is 1.44 times the minimum value. The ratio of maximum and minimum values of soil total porosity, capillary porosity and non-capillary porosity are 1.23 , 1.20 and 12.4 , respectively, among which non-capillary porosity shows the wide range. The $\mathrm{CV}$ is an index that represents the overall variation or heterogeneity of a given variable [7], and is the most important factor in describing the variability of a soil property [29]. $\mathrm{CV}<10 \%$ indicates weak variability, $\mathrm{CV}=10-100 \%$ indicates moderate variability, and $\mathrm{CV}>100 \%$ indicates high variability [33]. Among six measured parameters of the physical properties, the CV of soil bulk density, total porosity and capillary porosity are $9.82 \%, 4.48 \%$ and $3.73 \%$, respectively, with all three parameters showing weak variation. The relatively low $\mathrm{CV}$ of the above three properties suggest that some other factors affecting soil physical properties should be included in the model, such as parent material, soil erosion and land management practices [4]. Soil moisture, capillary water capacity and non-capillary porosity show moderate variation with $\mathrm{CV}$ values of $14.60 \%, 19.91 \%$ and $17.59 \%$, respectively. Similar results have been reported on soil capillary water capacity [51].

\section{Pearson Correlation Analysis of Soil Physical Properties}

Pearson correlation coefficient is a measure of the linear correlation between two variables. It has a value between 1 and -1 , where 1 is total positive linear correlation, 0 is no linear correlation and -1 is total negative linear correlation. The Pearson correlation coefficients among the soil physical properties are shown in Table 2. Soil bulk density shows a significant positive correlation with soil moisture and capillary water capacity with correlation coefficients of 0.85 and 0.91 , respectively. However, the correlation coefficients of soil bulk density with total porosity, capillary porosity and non-capillary porosity, are $-0.82,-0.71$ and -0.94 , respectively. Soil moisture and capillary water capacity shows a significantly positive correlation with a correlation coefficient of 0.84 ; however, soil moisture shows a significantly negative correlation with total porosity, capillary porosity, non-capillary porosity, with correlation coefficients of $-0.76,-0.67$ and -0.81 , respectively. By analyzing the spatial heterogeneity of soil physical properties in the South Sichuan Bamboo Sea, which is covered by the same type of purples soil, similar results were found [51]. The trend in the above correlations indicates that the physical properties of soil are closely related to human activities. That is to say, due to the strong disturbances of human activities in cultivated land, such as renovation of soil and fertilization, physical and structural properties of the soil are greatly changed, as are significant correlations between soil physical properties. Moreover, other factors, such as soil clay content, soil $\mathrm{pH}$, soil erosion and their interactions with precipitation and temperature, could also play important roles in affecting Pearson correlation of soil physical properties [52].

Table 1. Classical statistical results of soil physical properties.

\begin{tabular}{|c|c|c|c|c|c|c|c|}
\hline Item & Min & Max & Mean & SD & Kurtosis & Skewness & CV \\
\hline Bulk density $\left(\mathrm{g} / \mathrm{cm}^{3}\right)$ & 0.90 & 1.31 & 1.12 & 0.11 & -0.34 & -0.84 & 9.82 \\
\hline Soil moisture (\%) & 18.11 & 35.01 & 25.20 & 3.68 & 0.85 & 0.79 & 14.60 \\
\hline Capillary water capacity (\%) & 16.03 & 37.08 & 27.43 & 5.46 & -0.06 & -1.02 & 19.91 \\
\hline Total porosity (\%) & 53.09 & 65.12 & 57.86 & 2.59 & 0.59 & 0.49 & 4.48 \\
\hline Capillary porosity (\%) & 49.21 & 59.21 & 53.36 & 1.99 & 0.59 & 0.63 & 3.73 \\
\hline Non-capillary porosity (\%) & 3.22 & 6.32 & 4.49 & 0.79 & 0.326 & -0.87 & 17.59 \\
\hline
\end{tabular}

Descriptive statistics of bulk density, soil moisture, capillary water capacity, total porosity, capillary porosity and non-capillary porosity; Min = Minimum value; $\mathrm{Max}=$ Maximum value; $\mathrm{SD}=$ Standard deviation; and $\mathrm{CV}=$ Coefficient of variation 
Table 2. Pearson correlation analysis of soil physical properties.

\begin{tabular}{|c|c|c|c|c|c|c|}
\hline Item & $\begin{array}{c}\text { Bulk density } \\
\left(\mathrm{g} / \mathrm{cm}^{3}\right)\end{array}$ & $\begin{array}{c}\text { Soil moisture } \\
(\%)\end{array}$ & $\begin{array}{c}\text { Capillary water } \\
\text { capacity (\%) }\end{array}$ & $\begin{array}{c}\text { Total porosity } \\
(\%)\end{array}$ & $\begin{array}{c}\text { Capillary } \\
\text { porosity } \\
(\%)\end{array}$ & $\begin{array}{c}\text { Non-Capillary } \\
\text { porosity } \\
(\%)\end{array}$ \\
\hline Bulk density $\left(\mathrm{g} / \mathrm{cm}^{3}\right)$ & 1 & & & & & \\
\hline Soil moisture (\%) & $0.85^{* *}$ & 1 & & & & \\
\hline Capillary water capacity (\%) & $0.91^{* *}$ & $0.84^{*}$ & 1 & & & \\
\hline Total porosity (\%) & $-0.82^{* *}$ & $-0.76^{* *}$ & $-0.79^{* *}$ & 1 & & \\
\hline Capillary porosity (\%) & $-0.71^{* *}$ & $-0.67^{* *}$ & $-0.66^{* *}$ & $-0.97^{*}$ & 1 & \\
\hline Non-capillary porosity (\%) & $-0.94^{* *}$ & $-0.81^{* *}$ & $-0.94^{* *}$ & $-0.81^{*}$ & $0.66^{* *}$ & 1 \\
\hline
\end{tabular}

Descriptive statistics of bulk density, soil moisture, capillary water capacity, total porosity, capillary porosity, and non-capillary porosity. Number of samples is 150 .

*The correlation was significant at the 0.05 level.

**The correlation was significant at the 0.01 level.

\section{Spatial Variation Analysis of Soil Physical Properties}

\section{Semi-Variance Analysis of Soil Physical Properties}

The spatial dependence of variables was assessed using the nugget effect and nugget/sill ratio. A ratio $<25 \%$ means a strong dependence, while $25-75 \%$ and $>75 \%$ represent moderate and weak dependence, respectively [53]. The variable range is the distance over which the semi-variance reaches to the value of the sill. A sampling distance greater than the value of the range indicates that values of the variable mutually independent, and it thus exhibits no spatial autocorrelation.

The best-fitted model parameters and some spatial structural index are shown in Table 3. In this study, spherical and gaussian models were used to describe the semi-variograms of soil physical properties. The best models analyze the spatial structure and provide the input parameters for interpolation [6]. Characterization of soil physical variability indices (e.g., $\mathrm{C}_{0}, \mathrm{C}_{0}+\mathrm{C}, \mathrm{C}_{0} /\left(\mathrm{C}_{0}+\mathrm{C}\right)$ ) describe variations in different aspects of soil physical properties, which are consistent in their expression of the effect on soil physical properties. The difference in degree of spatial dependence is caused by random and structural factors. Soil bulk density, total porosity and capillary capacity of $\mathrm{C}_{0} /\left(\mathrm{C}_{0}+\mathrm{C}\right)$ show strong spatial dependence with values less than $25 \%$. However, soil moisture, capillary porosity and non-capillary porosity of $\mathrm{C}_{0} /\left(\mathrm{C}_{0}+\mathrm{C}\right)$ exhibit moderate spatial dependence with values between $25 \%$ and $75 \%$. Semi-variance analysis shows that the $\mathrm{C}_{0} /\left(\mathrm{C}_{0}+\mathrm{C}\right)$ of soil bulk density, total porosity and capillary capacity are $0.13,0.11$ and 0.09 , respectively, which are less than $25 \%$. The results show strong spatial auto-correlation, and are affected by soil type, parent material, topography and other structural factors. The $\mathrm{C}_{0} /\left(\mathrm{C}_{0}+\mathrm{C}\right)$ of soil moisture, capillary porosity and non-capillary porosity were $0.67,0.28$, and 0.69 , respectively, which show moderate spatial autocorrelation. Similar results were obtained by Bhanthumnavin et al. [54], who showed that spatial dependence was affected by natural factors such as parent material, topography, soil type and altitude, and that soil physical indicators had the direction of a homogenization trend. In addition, the coefficients of determination $\left(\mathrm{R}^{2}\right)$ of the soil physical parameters

Table 3. Semi-variogram model types and parameters of soil physical properti.

\begin{tabular}{|c|c|c|c|c|c|c|c|}
\hline Item & Model & $\mathrm{C}_{0}$ & $\mathrm{C}_{0}+\mathrm{C}$ & $\mathrm{C}_{0} / \mathrm{C}_{0}+\mathrm{C}$ & Range & $\mathrm{R}^{2}$ & Transformation \\
\hline Bulk density $\left(\mathrm{g} / \mathrm{cm}^{3}\right)$ & $\mathrm{I}$ & 0.03 & 0.23 & 0.13 & 167 & 0.92 & None \\
\hline Soil moisture (\%) & $\mathrm{I}$ & 0.02 & 0.03 & 0.67 & 234 & 0.81 & Log \\
\hline Capillary water capacity (\%) & $\mathrm{I}$ & 0.14 & 1.27 & 0.11 & 189 & 0.73 & Log \\
\hline Total porosity (\%) & II & 0.58 & 6.44 & 0.09 & 298 & 0.93 & None \\
\hline Capillary porosity (\%) & I & 0.25 & 0.89 & 0.28 & 121 & 0.91 & None \\
\hline Non-Capillary porosity (\%) & II & 0.36 & 0.52 & 0.69 & 166 & 0.92 & None \\
\hline
\end{tabular}

Descriptive statistics of bulk density, soil moisture, capillary water capacity, total porosity, capillary porosity and non-capillary porosity; Model I: Gaussian model; Model II: Spherical model 
Table 4. Cross-validation of prediction errors for ordinary kriging (OK) and empirical bayesian kriging (EBK) methods.

\begin{tabular}{|c|c|c|c|c|c|c|}
\hline Item & Methods & ME & RMSE & MSE & RMSSE & ASE \\
\hline \multirow{2}{*}{ Bulk density $\left(\mathrm{g} / \mathrm{cm}^{3}\right)$} & $\mathrm{OK}$ & -0.0002 & 0.0282 & -0.0081 & 1.1046 & 0.0257 \\
\hline & EBK & 0.0001 & 0.0278 & -0.0017 & 0.9426 & 0.0294 \\
\hline \multirow{2}{*}{ Soil moisture (\%) } & $\mathrm{OK}$ & 0.0095 & 1.1136 & 0.0098 & 1.0723 & 1.0415 \\
\hline & EBK & 0.0045 & 1.0595 & 0.0069 & 0.9831 & 1.0651 \\
\hline \multirow{2}{*}{ Capillary water capacity (\%) } & $\mathrm{OK}$ & -0.0013 & 1.4146 & 0.0032 & 1.4886 & 0.9383 \\
\hline & EBK & -0.0539 & 1.3134 & -0.0317 & 0.9285 & 1.3335 \\
\hline \multirow{2}{*}{ Total porosity (\%) } & $\mathrm{OK}$ & 0.0053 & 1.1425 & 0.0160 & 1.0246 & 1.1084 \\
\hline & EBK & -0.0062 & 1.1095 & -0.0044 & 1.0146 & 1.0871 \\
\hline \multirow{2}{*}{ Capillary porosity (\%) } & OK & 0.0157 & 1.1196 & 0.0106 & 0.9505 & 1.2244 \\
\hline & EBK & -0.0138 & 1.1283 & -0.0119 & 1.0329 & 1.0825 \\
\hline \multirow{2}{*}{ Non-Capillary porosity (\%) } & OK & 0.0009 & 0.1728 & 0.0076 & 1.8841 & 0.0928 \\
\hline & EBK & 0.0004 & 0.1669 & 0.0063 & 1.1094 & 0.0497 \\
\hline
\end{tabular}

Descriptive statistics of bulk density, soil moisture, capillary water capacity, total porosity, capillary porosity, and non-capillary porosity, ME = Mean-Error; RMSE = Root-Mean-Square-Error; MSE = Mean-Standardized-Error;

RMSSE $=$ Root-Mean-Square-Standardized-Error; ASE = Average-Standard-Error
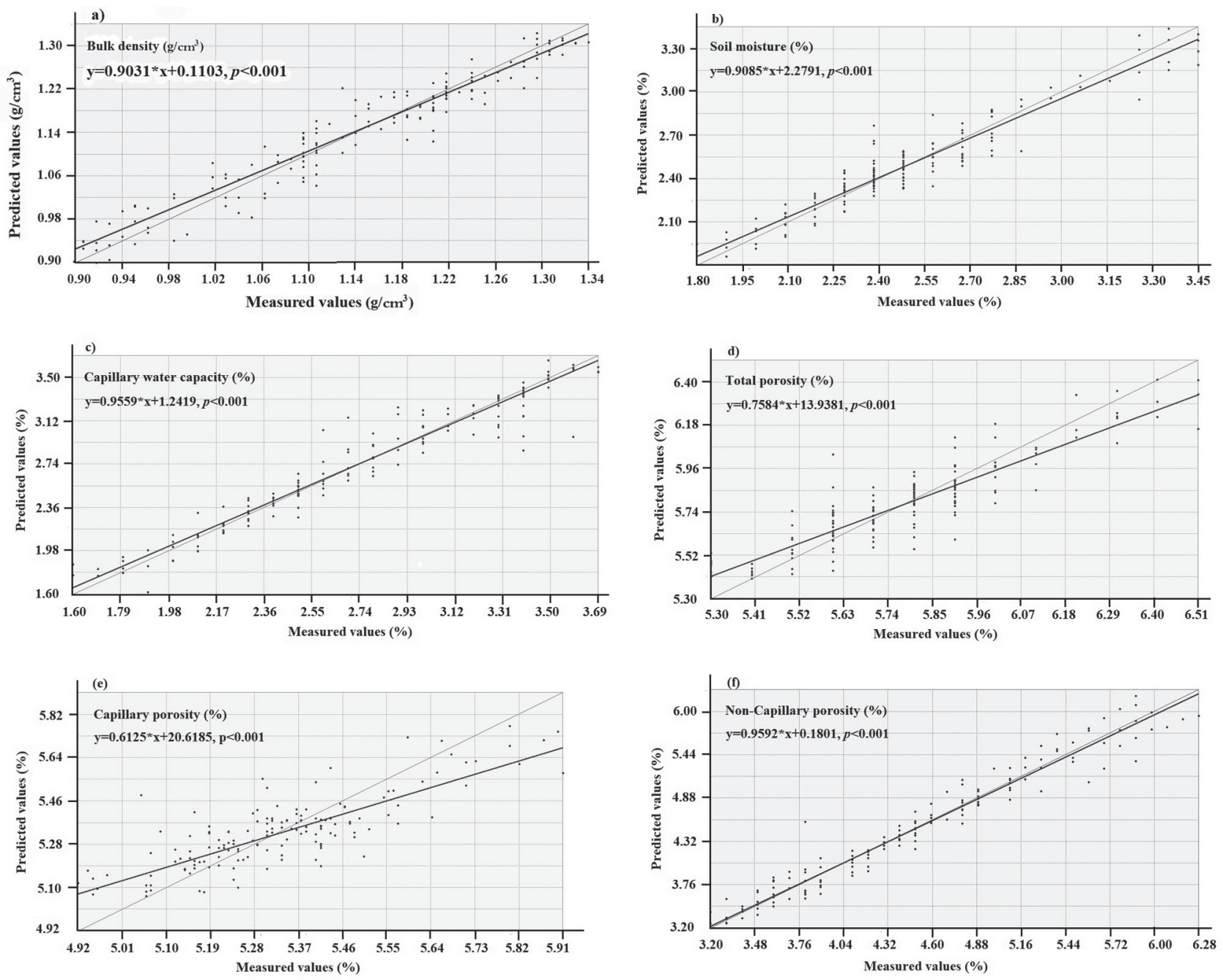

Fig. 2. Cross-validation of OK of soil physical properties. 
are close to 1 , indicating that high accuracy was achieved in the simulation of the theoretical models.

\section{Comparisons of Cross-Validation between $\mathrm{OK}$ and EBK}

Different scatter distribution patterns suggest that different methods could predict different values for the same point [4]. Table 4 shows the results of the crossvalidation of the $\mathrm{OK}$ and $\mathrm{BEK}$ methods. In theory, the best predicted results should be equal to the actual measured values. Because of the smoothing effect during the spatial interpolation process, the slope of the linear regression of the measured value against the predicted value are usually less than 1 . Cross-validation is a model validation technique for assessing how the results of a statistical analysis will generalize to an independent data set. It is mainly used in scenarios where the goal is prediction, and one seeks to estimate how accurately a predictive model will perform in practice. Therefore, statistical indices of error prediction can reflect the interpolation accuracy very well by cross-validation. A mean error (ME) value close to 0 indicates that the predicted value is unbiased, whereas a mean standardized error (MSE) value close to 0 and a root mean square standardized error (RMSSE) value close to 1 indicate that the standard error is accurate. A root mean square error (RMSE) value and an average standard error (ASE) value close to 0 indicate that the deviation between the predicted value and the measured value is small.

In order to compare the performance of the different interpolations, the ME, RMSE, MSE, RMSSE and ASE were calculated for the OK and EBK methods (Table 4). The results shows that the ME values of the two methods were all close to zero, which indicates that they were all relatively unbiased in interpolating the soil physical properties [4]. The ME values of soil bulk density, soil moisture, capillary porosity and non-capillary porosity obtained by the EBK method in this study were 0.0001 , $0.0045,-0.0138$ and 0.0004 , respectively, and are thus closer to 0 than those by the OK method. In addition, the RMSE values of soil bulk density, soil moisture, capillary water capacity, total porosity, capillary porosity and non-capillary porosity obtained by the EBK method were lower than those by the OK method, which proves
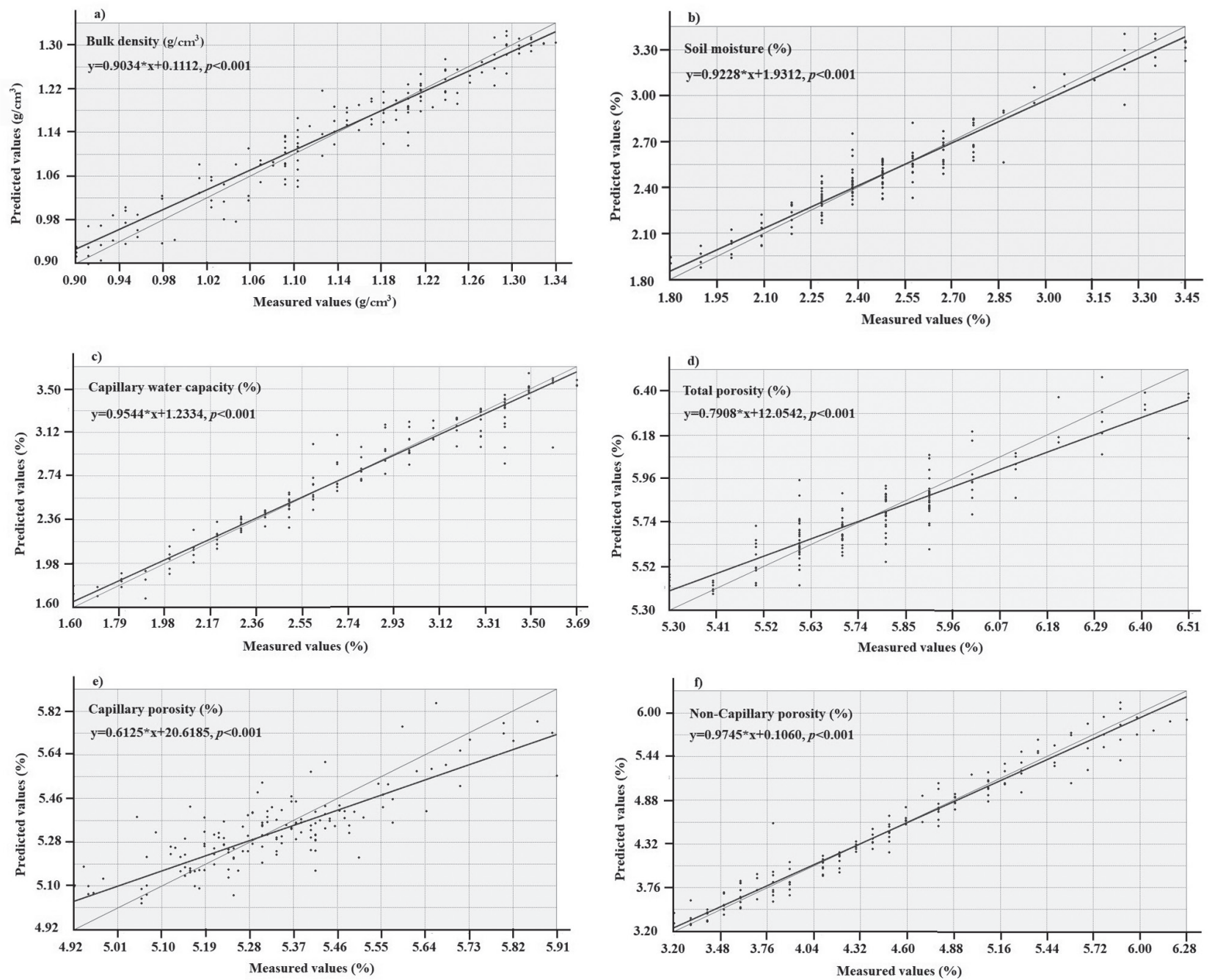

Fig. 3. Cross-validation of EBK of soil physical properties. 
that prediction by the EBK method obtained values with negligible deviation. The RMSSE values derived obtained by the EBK method are closer to 1 than those by the OK method, indicating that the standard error obtained by the EBK method was more accurate than those by the OK method. The RMSSE for total porosity, capillary porosity and non-capillary porosity obtained by the EBK method were lower than those by the OK method. The results indicate that the EBK interpolation method is more suitable for predicting the heterogeneity of the spatial distribution of the soil physical properties in the red beds region. In the prediction of soil physical properties the EBK method has the advantage of high precision over the OK method.

Low value of RMSE and ME indicated a good match between observed and predicted soil physical properties. Although OK methods offer better interpolation for estimating values of unmeasured locations [55-57], this research proved that the performance of EBK was better in comparison with $\mathrm{OK}$ interpolation models in spatial interpolation of soil physical properties in a red beds region.

Fig. 2 shows the cross validation interpolation graphs using the OK and EBK methods, and the relationship between measured values and predicted values for the sampling points. Matching points from the results of bulk density, water content, capillary moisture and non-capillary porosity were concentrated around the 1:1 reference line, which indicates that the predicted values in this range were very close to the measured values and achieved high precision in prediction. The slopes of the linear regression lines are similar, having values of bulk density of 0.9031 (OK) and 0.9034 (EBK), soil moisture of $0.9085(\mathrm{OK})$ and 0.9228 (EBK), capillary water capacity of 0.9559 (OK) and 0.9544 (EBK), total porosity of $0.7584(\mathrm{OK})$ and 0.7908 (EBK), capillary porosity of $0.6125(\mathrm{OK})$ and 0.6931 (EBK) and non-capillary porosity of $0.9592(\mathrm{OK})$ and 0.9745 (EBK). In other words, the slopes of the total porosity and capillary porosity regression functions were less than those of the bulk density, soil moisture, capillary water capacity and non-capillary porosity, and indicate relatively low precision in prediction. Related research showed that low correlations were found between the predicted and measured data because of a nonprobabilistic design [58]. What can be seen from the regression function and the cross-validation map of these two methods, is that the EBK method can be used to obtain more accurate interpolation results of spatial variability of soil physical properties in the red beds region. However, the scatter points lying outside of the $95 \%$ prediction intervals differed for the different interpolation methods [4]. Therefore, the appropriate method to study the variability of soil can effectively improve the characterization of soil in the study area, and provide a more scientific basis for the precise management of soil.

\section{Spatial Distribution Pattern of Soil Physical Properties}

The number of soil samples, the distance between sampling locations and the choice of interpolation are factors that affect the prediction of spatial distribution for soil properties [59, 60]. Generally, the larger the number of soil samples, the more accurate the kriging maps of soil properties $[60,61]$. The original datebase (150 soil samples) that we used in this study was
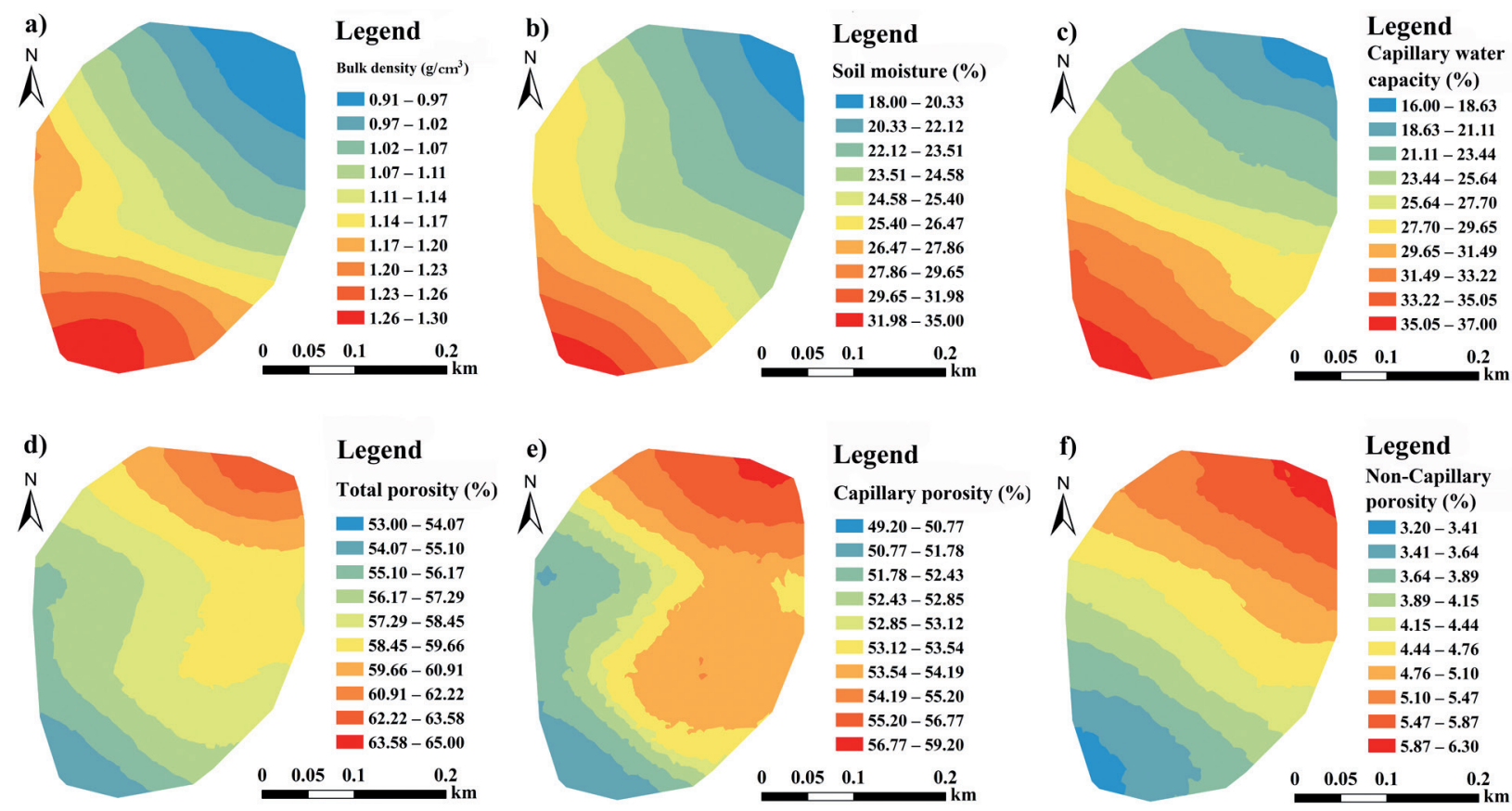

Fig. 4. Patterns of spatial distribution of OK of soil physical properties. 

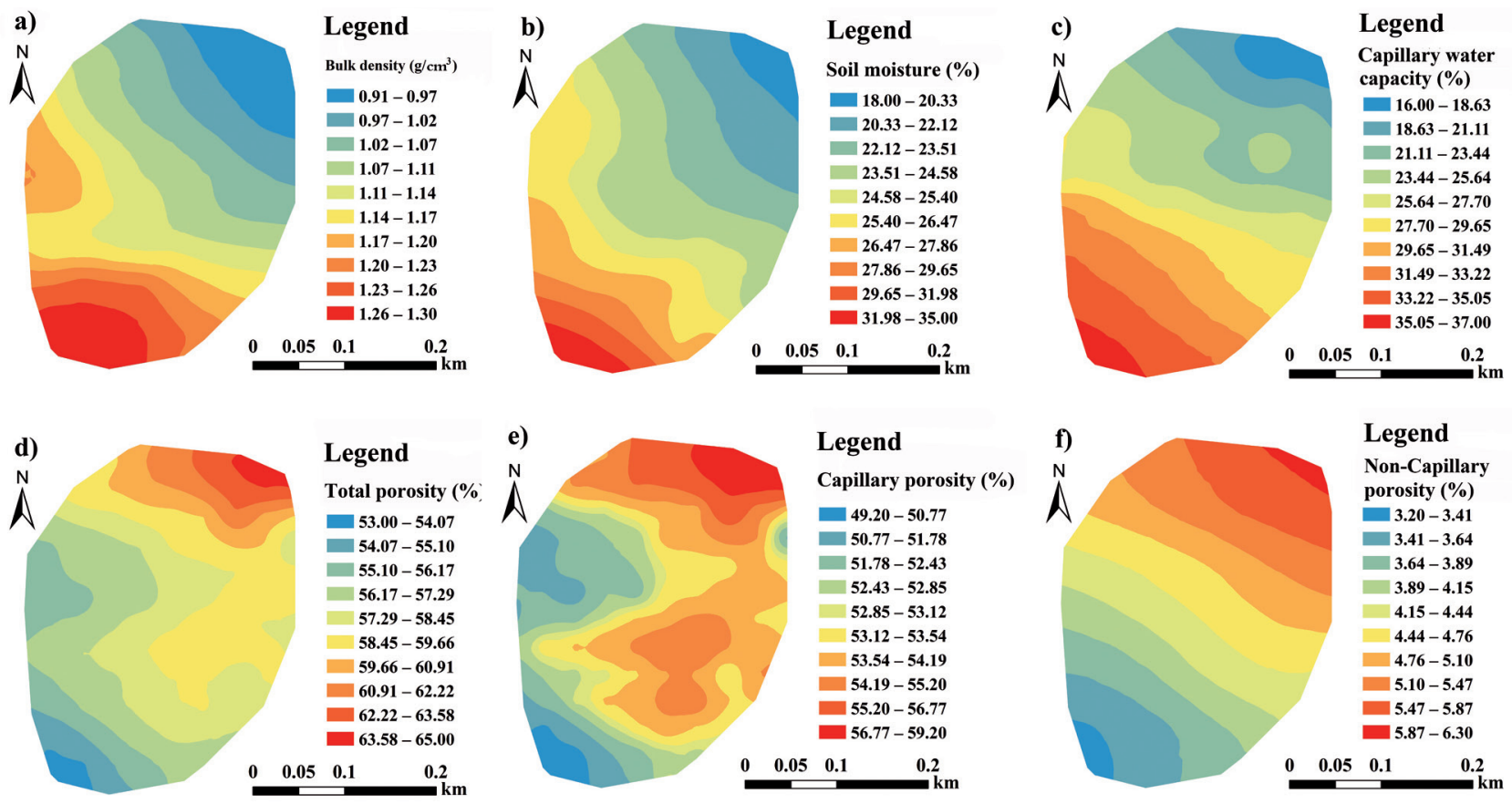

Fig. 5. Patterns of spatial distribution of EBK of soil physical properties.

collected from a small area, thus the sample number for spatial interpolation when compared with other research.

As shown in Figs 4 and 5, the spatial distribution patterns of the soil physical properties obtained from OK and EBK are broadly consistent and exhibit a block and ladder-shaped spatial distribution pattern. There were also differences between the two methods. The results generally show an increasing trend in soil bulk density, soil moisture and capillary water capacity with zonal distribution from northeast to southwest, while a decreasing trend of soil total porosity, capillary porosity and non-capillary porosity with zonal distribution from northeast to southwest. Among the former three soil properties, the distribution pattern of soil bulk density and soil moisture have the features of zonal and island, with the highest values in study area occurring in the southwestern corner. The distribution pattern of soil capillary water capacity shows a ladder distribution, and the low values occurred in the northeastern corner. The distribution pattern of soil total porosity and capillary porosity shows island shape, with low values seen both southwest and west of the map. The non-capillary porosity shows ladder-shaped distribution, with the highest values in the northeastern corner. These results are mainly because the southern part of the area is farmland, which shows the importance of land use as the main influential factor and is in accordance with the conclusion that land use is a important factor in spatial variability in soil $\mathrm{pH}$ [4]. Spatial Variability in Soil $\mathrm{pH}$ and Land Use as the Main Influential Factor in the Red Beds of the Nanxiong Basin, China. Peer J. 7: e6342, 2019. Soil is often affected by fertilization, tillage and other human activities, which lead to increased soil fertility and improving soil structure. Therefore, the porosity and water-holding capacity of the soil in the northeastern region is also suitable for agricultural soil. However, further study at smaller scales in this area is needed to clarify this issue.

The OK interpolation produced many small patches and surface irregularities (Fig. 3e), while EBK created a smoother surface. There were some points on the map produced by $\mathrm{OK}$ attributed to noise, or which may be caused by human disturbance. Gao et al. (2016) also arrived at a similar conclusion, and considered that human disturbance is one of the main reasons for the spatial distribution of soil physical properties.

Taking into account the comparison of interpolation performance discussed in sect. comparisons of crossvalidation between $\mathrm{OK}$ and $\mathrm{EBK}$, we concluded that the map produced by EBK is more accurate than by the OK method. Therefore, the spatial distribution pattern of soil physical properties obtained by the EBK method had higher precision. The EBK method did provide the best linear unbiased estimations and information on the spatial patterns of estimation errors.

\section{Conclusions}

Soil physical properties in surface soils were investigated in a relatively small area in the red beds region of Nanxiong Basin, China. According to analysis with Pearson correlation, soil bulk density was significantly positively correlated with soil moisture and capillary water capacity $(\mathrm{p}<0.01)$, where the correlation coefficients were 0.85 and 0.91 , respectively, but were significantly negatively correlated with total porosity, capillary porosity and non-capillary porosity, where 
the correlation coefficients were $0.82,0.71$ and 0.94 , respectively $(p<0.01)$, indicating that soil physical properties were controlled by both intrinsic and extrinsic factors. Soil bulk density and total porosity showed weak variation and strong spatial dependence at this regional scale, as indicated by the low $\mathrm{CV}$ values and nugget-to-sill ratios.

Two spatial interpolation methods were compared: OK and EBK. Spherical and Gaussian models performed well in describing the spatial variability of soil physical properties. Although $\mathrm{OK}$ is relatively simple and userfriendly, the interpolation by $\mathrm{OK}$ is less accurate than by EBK. Cross-validation analysis demonstrated that EBK performed better than $\mathrm{OK}$ for the spatial interpolation of soil physical properties in a smaller area of the red beds region. Areas of high soil total porosity, capillary porosity and non-capillary porosity were located in the northeast of the region, and were possibly associated with human factors. The interpolation accuracy of the soil physical properties could be further improved by including more information on these ancillary variables with more kriging methods. The OK and EBK methods showed similar spatial distribution of the soil physical properties in the study area, demonstrating the reasonable suitability of OK and EBK in spatial interpolation of soils. In addition, comparison of the maps of the spatial distribution of soil physical properties indicated that EBK can provide a more accurate distribution map of soil physical properties for the study area. EBK exhibits better performance in interpolation of soil physical properties at relatively smaller scale than by the OK method. EBK produced finer areas of predicted soil physical properties than OK, highlighting the necessity of choosing the most appropriate method in studying the spatial distribution of soil properties.

\section{Acknowledgements}

This work was supported by the National Natural Science Foundation of China (grant No. 41771088 and 51779279) Fundamental Research Funds for the Central Universities (SWU 118202), and the project 'National Danxia Landform Basic Data Survey' from the Special Program for Key Basic Research of the Chinese Ministry of Science and Technology (grant No. 2013FY111900).

\section{Conflict of Interest}

The authors declare no conflict of interest.

\section{References}

1. IQBAL J., THOMASSON J.A., JENKONS J.N., OWENS P.R., WHISLER F.D. S. Soil Science Society of America Journal. 69 (4), 1338, 2005.
2. LIU H., LIU G., ZHOU Y., HE C. Spatial distribution and influence analysis of soil heavy metals in a hilly region of sichuan basin. Polish Journal of Environmental Studies, 26 (2), 725, 2017.

3. DUNIEC G., MAZUR A. Modified description of soil processes vs. quality of numerical weather forecasts "Bare Soil" case. Ecological Chemistry \& Engineering S. 22 (4), 659, 2016.

4. LIU Z.P, SHAO M.A., WANG Y.Q. Scale-dependent correlations between soil properties and environmental factors across the Loess Plateau of China. Soil Research. 51 (2), 112, 2013.

5. ZHANG H.H., NA T., ZHANG Q. Spatial heterogeneity of loess contour tilled microtopographic slope in rainfall erosion. Soil Science and Plant Nutrition. 62 (5-6), 409, 2016.

6. GUAN F., XIA M., TANG X., FAN S. Spatial variability of soil nitrogen, phosphorus and potassium contents in moso bamboo forests in yong'an city, china. Catena. 150, 161, 2017.

7. LIU Z.P., SHAO M.A., WANG Y.Q. Large-scale spatial variability and distribution of soil organic carbon across the entire Loess Plateau, China. Soil Research. 50 (2), 114, 2012.

8. SØVIK A.K, AGAARD P. Spatial variability of a solid porous framework with regard to chemical and physical properties. Geoderma. 113, 47, 2003.

9. SI B.C. Spatial Scaling Analyses of Soil Physical Properties: A Review of Spectral and Wavelet Methods. Vadose Zone Journal. 7 (2), 547, 2008.

10. WANG Y.Q., ZHANG X.C., HUANG C.Q. Spatial variability of soil total nitrogen and soil total phosphorus under different land uses in a small watershed on the Loess Plateau, China. Geoderma. 150 (1-2), 141, 2009.

11. GOOVAERTS P. Geostatistics in soil science: state-of-theart and perspectives. Geoderma. 89 (1-2), 1, 1999.

12. HARUNA S.I., NKONGOLO N.V. Variability of Soil Physical Properties in a Clay-Loam Soil and Its Implication on Soil Management Practices. Isrn Soil Science. 2013 (2013), 1, 2015.

13. GOOVAERTS P. Geostatistical tools for characterizing the spatial variability of microbiological and physico-chemical soil properties. Biology and Fertility of Soils. 27 (4), 315, 1998.

14. NIELSEN D.R. Spatial variability of field-measured soil-water properties. Hilgardia. 42 (7), 215, 1973.

15. KANG J., JIN R., LI X., ZHANG Y. Block Kriging With Measurement Errors: A Case Study of the Spatial Prediction of Soil Moisture in the Middle Reaches of Heihe River Basin. IEEE Geoscience \& Remote Sensing Letters. 99, 1, 2017.

16. SERRANO J.M., SHAHIDIAN S., SILVA J.M.D. Spatial variability and temporal stability of apparent soil electrical conductivity in a Mediterranean pasture. Precision Agriculture. 18 (2), 1, 2017.

17. WALTER C., MCBRATNEY A.B., DOUAOUI A. MINASNY B., WALTER C. Spatial prediction of topsoil salinity in the Chelif Valley, Algeria, using local ordinary kriging with local variograms versus whole-area variogram. Soil Research. 39 (2), 259, 2001.

18. KNOTTERS M., BRUS D.J., VOSHAAR J.H.O. A comparison of kriging, co-kriging and kriging combined with regression for spatial interpolation of horizon depth with censored observations. Geoderma. 67 (3), 1995. 
19. YANG Q., JIANG Z., MA Z., LI H. Spatial prediction of soil water content in karst area using prime terrain variables as auxiliary cokriging variable. Environmental Earth Sciences. 72, 4303, 2014.

20. MICHAEL S., RUPRECHT H., PETER W., ROBIN G. Area-to-point kriging of soil phosphorus composite samples. Communications in Soil Science \& Plant Analysis. 43 (7), 1024, 2012.

21. HU S., CHENG Q., WANG L., XU D. Modeling land price distribution using multifractal IDW interpolation and fractal filtering method. Landscape \& Urban Planning. 110 (1), 25, 2013.

22. VAHEDI A.A. Monitoring soil carbon pool in the Hyrcanian coastal plain forest of Iran: Artificial neural network application in comparison with developing traditional models. Catena. 152, 182, 2017.

23. ROMANO N., SANTINI A. Effectiveness of using pedo-transfer functions to quantify the spatial variability of soil water retention characteristics. Journal of Hydrology. 202 (1-4), 137, 1997.

24. BAKHSH A., COLVIN T.S., JAYNES D.B., KANWAR R.S., TIM U.S. Using soil attributes and gis for interpretation of spatial variability in yield. Transactions of the Asae. 43 (4), 819, 2000.

25. LI J., HEAP A.D. A review of comparative studies of spatial interpolation methods in environmental sciences: performance and impact factors. Ecological Informatics. 6, 228, 2011.

26. SAMSONOVA V.P., BLAGOVESHCHENSKII Y.N., MESHALKINA Y.L. Use of Empirical Bayesian kriging for revealing heterogeneities in the distribution of organic carbon on agricultural lands. Eurasian Soil Science. 50 (3), 305, 2017.

27. MULCAN A., MITSOVA D., HINDLE T., HANSON H., COLEY C. Marine Benthic Habitats and Seabed Suitability Mapping for Potential Ocean Current Energy Siting Offshore Southeast Florida. Journal of Marine Science and Engineering. 3, 276, 2015.

28. WEI J.B., XIAO D.N., ZENG H., FU Y.K. Spatial variability of soil properties in relation to land use and topography in a typical small watershed of the black soil region, northeastern china. Environmental Geology. 53 (8), $1663,2008$.

29. WANG Y., LI Y., XIAO D. Catchment scale spatial variability of soil salt content in agricultural oasis, Northwest China. Environmental Geology. 56 (2), 439, 2008.

30. LIU S.L., LI Y., WU J.S., HUANG D.Y., SU Y.R., WEI W.X. Spatial variability of soil microbial biomass carbon, nitrogen and phosphorus in a hilly red soil landscape in subtropical china. Soil Science \& Plant Nutrition. 56 (5), 693, 2010.

31. FU T., CHEN H., ZHANG W., NIE Y., GAO P., WANG K. Spatial variability of surface soil saturated hydraulic conductivity in a small karst catchment of southwest china. Environmental Earth Sciences. 74 (3), 2381, 2015.

32. HAN F.P., ZHENG J.Y., HU W., ZHANG X.C. Spatial variability and distribution of soil nutrients in a catchment of the loess plateau in china. Acta Agriculturae Scandinavica. 60 (1), 48, 2010.

33. FANG X., XUE Z., LI B., AN S. Soil organic carbon distribution in relation to land use and its storage in a small watershed of the loess plateau, china. Catena. 88 (1), 6, 2012.

34. LIU Z.P., SHAO M.A., WANG Y.Q. Large-scale spatial interpolation of soil $\mathrm{pH}$ across the Loess Plateau, China. Environ. Earth Sci. 69, 2731, 2012.
35. WANG Z.M., ZHANG B., SONG K.S., LIU D.W., REN C.Y. Spatial variability of soil organic carbon under maize monoculture in the Song-Nen Plain, Northeast China. Pedosphere. 20, 80, 2010.

36. UYGUR V., IRVEM A., KARANLIK S., AKIS R. Mapping of total nitrogen, available phosphorous and potassium in amik plain, turkey. Environmental Earth Sciences. 59 (5), 1129, 2010.

37. ALLAIREA S.E., CAMBOURIS A.N., LAFONDA J.A., LANGEA S.F., PELLETIERC B., DUTILLEUL P. Spatial variability of potato tuber yield and plant nitrogen uptake related to soil properties. Agronomy Journal. 106, 851, 2014.

38. YANG Z.P., OOUYANG H., ZHANG X., XU X.L., ZHOU C.P., YANG W.B. Spatial variability of soil moisture at typical alpine meadow and steppe sites in the QinghaiTibetan Plateau permafrost region. Environmental Earth Sciences. 63, 477, 2011.

39. WANG H.J., SHI X.Z., YU D.S, WEINDORF D.C., HUANG B., SUN W.X., RITSEMA C.J, MILNE E. Factors determining soil nutrient distribution in a smallscaled watershed in the purple soil region of Sichuan Province, China. Soil and Tillage Research. 105, 300, 2008.

40. CHENG X.F., SHI X.Z., YU D.S., PAN X.Z., WANG H.J., SUN W.X. Using GIS spatial distribution to predict soil organic carbon in subtropical China. Pedosphere. 14, 425, 2004.

41. LI Q.Q., LUO Y.L., WANG C.Q., LI B., ZHANG X., YUAN D.G., GAO X.S., ZHANG H. Spatiotemporal variations and factors affecting soil nitrogen in the purple hilly area of Southwest China during the 1980s and the 2010s. Science of the Total Environment. 547, 173, 2016.

42. KIMIAGHALAM N., CLARK S.P., AHMARI H. An experimental study on the effects of physical, mechanical, and electrochemical properties of natural cohesive soils on critical shear stress and erosion rate. International Journal of Sediment Research. 31, 1, 2016.

43. WEI Y., WU X., CAI C. Splash erosion of clay-sand mixtures and its relationship with soil physical properties: The effects of particle size distribution on soil structure. Catena. 135, 254, 2015.

44. YAN L.B., HE R.X., MILICA K.G., LUO G.S., PENG H., QIU J.X. The Dynamic Change of Vegetation Cover and Associated Driving Forces in Nanxiong Basin, China. Sustainability. 9 (3), 443, 2017.

45. LIU Z.P., SHAO M.A., WANG Y.Q. Effect of environmental factors on regional soil organic carbon stocks across the Loess Plateau region, China. Agriculture, Ecosystems \& Environment. 142, 184, 2011.

46. YANG J., CHEN H., NIE Y., ZHANG W., WANG K. Spatial variability of shallow soil moisture and its stable isotope values on a karst hillslope. Geoderma. 264, 61, 2016.

47. YASREBI J., SAFFARI M., FATHI H., KARIMIAN N., MOAZALLAHI M., GAZNI R. Evaluation and comparison of ordinary kriging and inverse distance weighting methods for prediction of spatial variability of some soil chemical parameters. Research Journal of Biological Sciences. 4 (1), 385, 2012.

48. WEBSTER R., OLIVER M.A. Geostatistics for environmental scientists (Statistics in Practice). Chichester, UL.: John Wiley \& Sons, 2011.

49. KRIVORUCHKO K. Empirical bayesian kriging. ArcUser Fall. 6, 2012. 
50. LIU Z.P., SHAO M.A., WANG Y.Q. Spatial patterns of soil total nitrogen and soil total phosphorus across the entire Loess Plateau region of China. Geoderma. 197-198 (3), 67, 2013.

51. GAO Q.W., DAI B., LUO C.D., LIU L., MA D., ZHANG C.C. Spatial heterogeneity of soil physical properties in Phyllostachys heterocycla cv pubescens forest, South Sichuan Bamboo Sea. Acta Ecologica Sinica. 36 (8), 2255, 2016.

52. BOGUNOVIC I., PEREIRA P., BREVIK E.C. Spatial distribution of soil chemical properties in an organic farm in Croatia. Science of the Total Environment. 584-585, 535, 2017.

53. CAMBARDELLA C.A., MOORMAN T.B., PARKIN T.B., KARLEN D.L., TURCO R.F., KONOPKA A.E. Field-Scale Variability of Soil Properties in Central Iowa Soils. Soil Science Society of America Journal. 58 (5), 1501, 1994.

54. JABRO J.D., STEVENS B.W., EVANS R.G. Spatial relationships among soil physical properties in a grass-alfalfa hay field. Soil science. 171, 719, 2006.

55. BURGESS T.M., WEBSTER R. Optimal interpolation and isarithmic mapping of soil properties. European Journal of Soil Science. 31, 315, 1980.
56. TRIPATHI R., NAYAK A.K., SHAHID M., RAJA R., PANDA B.B., KUMAR A., LAL B., GAUTAM P., SAHOO R.N. Characterizing spatial variability of soil properties in salt affected coastal India using geostatistics and kriging. Arabian Journal of Geosciences. 8, 10693, 2015.

57. VENTERIS E.R., BASTA N.T., BIGHAM J.M., REA R. Modeling spatial patterns in soil arsenic to estimate natural baseline concentrations. Journal of environmental quality. 43, 936, 2014.

58. VERONESI F., CORSTANJE R., MAYR T. Landscape scale estimation of soil carbon stock using 3D modelling. Sci. Total Environ. 487, 578, 2014.

59. XIE Y.F., CHEN T.B., LEI M., YANG J., GUO Q.J., SONG B., ZHOU X.Y. Spatial distribution of soil heavy metal pollution estimated by different interpolation methods: Accuracy and uncertainty analysis. Chemosphere. 82, 468, 2011.

60. KRAVCHENKO A. Influence of spa-tial structure on accuracy of interpo-lation methods. Soil Science Society of America Journal. 67, 1564, 2003.

61. MUELLER T., PIERCE F., SCHABENBERGER O., WAMCKE D. Map quality for site-specific fer-tility management. Soil Science So-ciety of America Journal. 65, 1547, 2001. 